\title{
Changes in circulating lipids level over time after acquiring HCV infection: results from ERCHIVES
}

\author{
Adeel A. Butt ${ }^{1,2,3,4^{*}}$, Peng Yan ${ }^{1}$, Tracey G. Simon ${ }^{5}$, Raymond T. Chung ${ }^{5}$, Abdul-Badi Abou-Samra ${ }^{4}$
} and for the ERCHIVES study team

\begin{abstract}
Background: Changes in lipid levels over time after acquiring HCV infection, and how they differ from HCV-uninfected persons are unknown.

Methods: We used ERCHIVES to identify those with a known HCV seroconversion window and persistently negative controls. We excluded subjects with HIV and hepatitis B and those who received lipid lowering agents. Total Cholesterol $(\mathrm{TC})$, low-density lipoproteins (LDL), high-density lipoproteins (HDL), triglycerides (TG) and non-HDL cholesterol were retrieved at yearly intervals and plotted over time.

Results: Among 1,270 HCV+ and 5,070 HCV- subjects, median age [IQR] was 47[37,53] for HCV+ and 52[47,57] for the HCV- group; $69 \%$ were White and $91 \%$ were males in each group. Mean BMI [SD] was 26.94[6.73] in the HCV+ and 28.15 [5.98] in the HCV-group $(P<0.001)$. Over a 10-year follow-up period among HCV+ persons, TC decreased by (mean (SD) $\mathrm{mg} / \mathrm{dL})$ 12.06(36.95), LDL by 9.22(31.44), TG by 13.58(87.01) and non-HDL-C by 12.55(35.14). Among HCV- persons, TC cholesterol decreased by 4.15(31.21), LDL by 4.16(26.51); TG by 4.42(82.34) and non-HDL-C by 5.78(30.17).

Conclusions: After HCV acquisition, TC, LDL, TG and non-HDL-C progressively decline over time independent of BMI and liver fibrosis. Consequences of lipid changes and the need and optimal timing of lipid lowering therapy in HCV+ persons require further study.
\end{abstract}

Keywords: HCV, Lipid, Cholesterol, LDL, ERCHIVES, Seroconversion

\section{Background}

Hepatitis $\mathrm{C}$ virus $(\mathrm{HCV})$ infection has been associated with alterations in lipid levels. Persons with HCV infection have significantly lower total cholesterol (TC), low density lipoprotein (LDL) and triglyceride (TG) levels compared with demographically similar $\mathrm{HCV}$ uninfected controls. In a previous study of 82,083 HCV infected and $89,582 \mathrm{HCV}$ uninfected controls, TC was $32 \mathrm{mg} / \mathrm{dL}$ lower, LDL was $18 \mathrm{mg} / \mathrm{dL}$ lower and TG were $25 \mathrm{mg} / \mathrm{dL}$ lower among HCV infected persons. [1] Other studies have shown similar associations.[2-4] Some previous reports offer a cross-sectional comparison at baseline for

\footnotetext{
* Correspondence: aabutt@pitt.edu

'VA Pittsburgh Healthcare System, 3601 Fifth Avenue, Suite 3A, Pittsburgh, PA 15213, USA

${ }^{2}$ University of Pittsburgh School of Medicine, Pittsburgh, PA, USA

Full list of author information is available at the end of the article
}

those particular studies and do not account for duration of $\mathrm{HCV}$ infection or changes in lipid profile over time. Others have reported on changes in lipid profiles after treatment for HCV.[5-8] To our knowledge, no studies have reported the changes in lipid profile after $\mathrm{HCV}$ acquisition and how they compare with demographically similar HCV uninfected persons.

It is currently unknown whether the changes in lipid profile among HCV infected persons are present even at time of HCV acquisition thus reflecting differences in demographic, behavioral and anthropometric parameters before infection or whether $\mathrm{HCV}$ infection itself triggers changes in the lipid profile. Temporal changes in lipid profile over time after $\mathrm{HCV}$ acquisition are also unknown. We used a previously described cohort with a known seroconversion timeframe within the Electronically Retrieved Cohort of HCV Infected Veterans (ERCHIVES) [9] to 
determine the changes in lipid profile over time among $\mathrm{HCV}$ infected persons after seroconversion and comparable $\mathrm{HCV}$ uninfected controls.

\section{Methods}

\section{Study population}

Construction of ERCHIVES has been described in several previous publications.[1, 10-18] Briefly, ERCHIVES contains all $\mathrm{HCV}$ infected persons identified via a positive $\mathrm{HCV}$ antibody test within the Veterans Affairs Healthcare System (VA) nationally between 2002-2013. Controls are age (5-year blocks), race and gender matched (1:1) with a negative HCV antibody test in the same year as the positive test for $\mathrm{HCV}$ infected group. Demographic, clinical, laboratory, pharmacy and mortality data are extracted from various national VA repositories and merged using scrambled social security numbers accordingly to a well-established algorithm.

For the current study, we identified persons within ERCHIVES with a first negative $\mathrm{HCV}$ antibody test followed by a positive $\mathrm{HCV}$ antibody test and no subsequent negative $\mathrm{HCV}$ antibody test. We excluded persons with HIV infection and a positive hepatitis B surface antigen (HBsAg). We also excluded persons with no lipid profile measurement at baseline and no measurement $>24$ months after baseline. We further excluded persons with missing or undetectable HCV RNA and baseline and those who were prescribed any lipid lowering agents for $>28$ days. Persons who received $\mathrm{HCV}$ treatment were censored at the time of treatment initiation. For each person finally identified, we identified up to four controls, matched on age (5-year blocks), race and gender, who had at least one negative $\mathrm{HCV}$ antibody test within 12 months of the first positive HCV antibody test among the seroconversion group. Controls were further required to have at least one more negative $\mathrm{HCV}$ antibody test to account for the testing bias for the seroconversion group, and no positive $\mathrm{HCV}$ antibody test ever after. Those with HIV infection, positive hepatitis B surface antigen, missing lipid profiles and who received lipid lowering agents were excluded similar to the seroconversion group.

\section{Measurements}

Lipid profiles were obtained during the course of routine clinical care. Since these values were obtained from electronic medical records, the proportion of persons who were fasting at time of testing is not known. Baseline value was taken to be the average of two most recent values prior to baseline. Lipid profiles were subsequently retrieved on yearly basis, using the values closest to the yearly time points. Non-HDL cholesterol (non-HDL-C) was calculated by subtracting HDL cholesterol from TC. Comorbidities were defined using lab values and/or disease codes using International Classification of Diseases, Ninth Revision, Clinical Modification (ICD-9 CM) as previously described.[1,9] Use of lipid lowering agents was defined as prescription of any drug approved for the treatment of elevated lipid levels for $>28$ days. Body mass index (BMI) was calculated as weight divided by the square of height $\left(\mathrm{kg} / \mathrm{m}^{2}\right)$ and categorized into underweight (BMI < 18.5), normal weight (BMI 18.5-24.9), overweight (BMI 25.0-29.9) and obese (BMI $\geq 30.0$ ). Degree of liver fibrosis was measured by using FIB-4 score, calculated as follows:

$$
\begin{aligned}
\text { FIB- } 4= & \text { age }[\text { years }] \\
& \times \text { AST }[\mathrm{IU} / \mathrm{L}] / \text { platelet count }\left[\text { platelets } \times 10^{9} / \mathrm{L}\right] \\
& \times\left(\mathrm{ALT}^{1 / 2}[\mathrm{IU} / \mathrm{L}]\right)
\end{aligned}
$$

\section{Analysis}

Baseline demographic and clinical characteristics and lipid profile were compared between HCV infected and uninfected persons using chi-square for dichotomous and $t$-test for continuous variables. We plotted changes in each of the lipid fractions, TC, LDL, HDL, TG and non-HDL-C, over time for HCV infected and uninfected persons. To understand the changes in lipid profile, we also tabulated and plotted each lipid fraction over time by BMI category (at baseline) and HCV genotype.

We performed additional analysis when plotting by HCV status, adjusting for severity of liver fibrosis using time-updated FIB-4 scores. A $p$-value of $<0.05$ was considered significant where comparisons were made. We used SAS ${ }^{\bullet}$ (SAS Institute Inc., Cary, NC) and Stata $^{\circ}$ version 11 (Stata Corp, College Station, TX) for statistical analyses.

\section{Regulatory approvals}

The study was approved by the Institutional Review Board at VA Pittsburgh Healthcare System. Appropriate approvals were obtained from each of the databases from where data were retrieved.

\section{Results}

\section{Baseline characteristics}

Within ERCHIVES we identified a total of 10,769 persons with a known window for HCV seroconversion (Fig. 1). After excluding those with HIV infection $(N=594)$, positive hepatitis B surface antigen $(N=894)$, missing lipid profiles or HCV RNA at baseline $(N=4,432)$ and those with undetectable HCV RNA at baseline $(N=1,873)$, there were 1,270 persons available for analysis. We identified $5,070 \mathrm{HCV}$ uninfected controls matched on the criteria described above. Median age [IQR] was 47 [37,53] for $\mathrm{HCV}+$ and $52[47,57]$ for the HCV-group. There were 69 \% White, 20 \% Black and 3 \% Hispanics and $91 \%$ were 


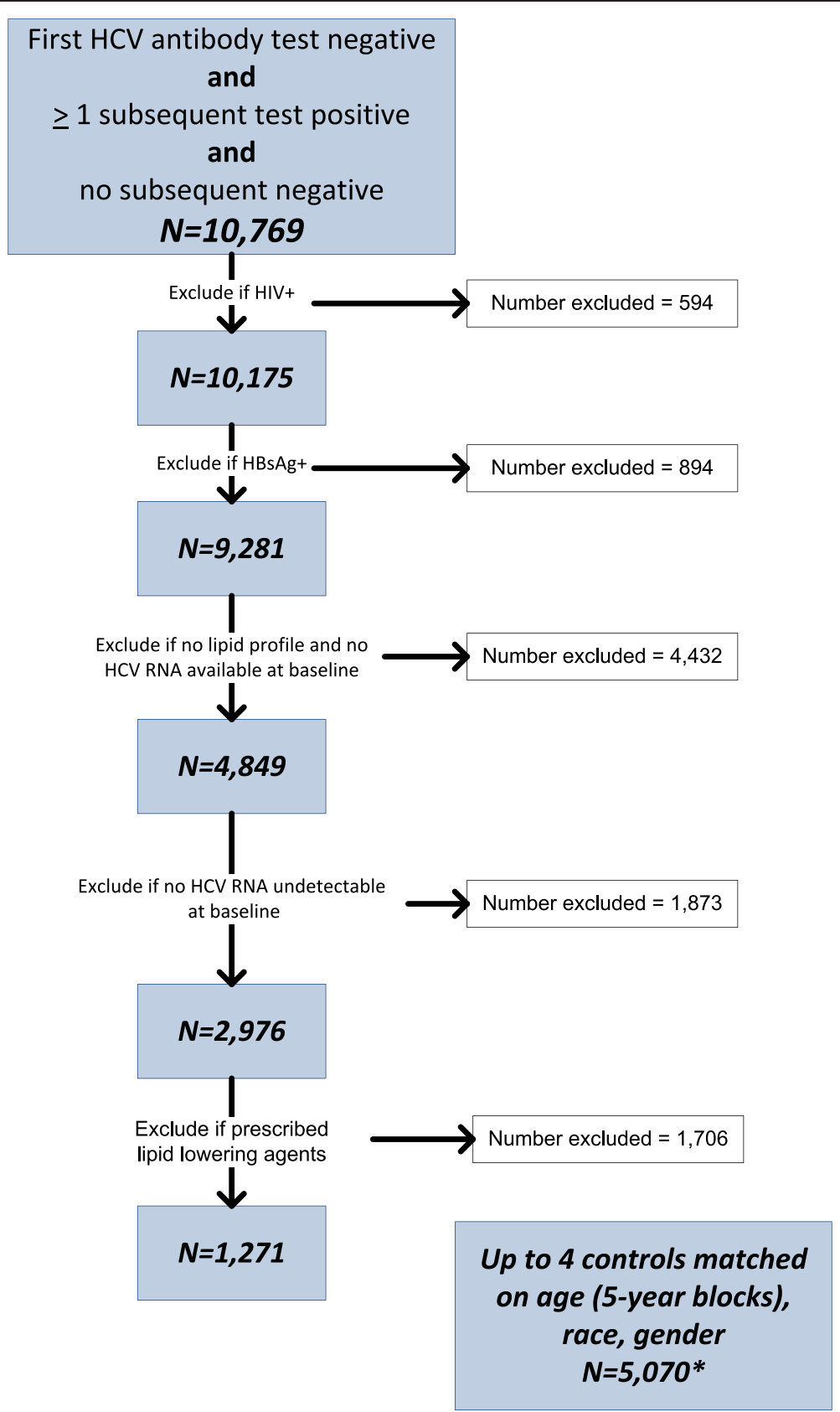

Fig. 1 Study flow sheet

male in each group. (Table 1) Mean BMI [SD] was 26.94 [6.73] in the HCV+ and 28.15 [5.98] in the HCV- group $(P<0.001)$. The prevalence of hypertension was lower while alcohol and drug abuse and dependence diagnoses were higher among $\mathrm{HCV}+$, compared with $\mathrm{HCV}$ - persons. Prevalence of stage 3-5 chronic kidney disease and cardiovascular disease was similar in both groups.

There were small but statistically significant differences in all lipid fractions between $\mathrm{HCV}+$ and $\mathrm{HCV}-$ groups. (Table 1) Total cholesterol, LDL and non-HDL-
C were lower while TG and HDL was higher among $\mathrm{HCV}$ infected compared with $\mathrm{HCV}$ uninfected persons.

\section{Changes in lipid profile over time}

Over the period of follow up, there were significant changes in most lipid fractions. All non-HDL lipid fractions declined over time for both $\mathrm{HCV}+$ and $\mathrm{HCV}$ - persons, with much larger declines observed in $\mathrm{HCV}+$ compared with $\mathrm{HCV}$ - persons (Fig. 2). There was no consistent pattern of change in lipid fractions by BMI 
Table 1 Baseline characteristics

\begin{tabular}{|c|c|c|c|}
\hline \multirow[t]{2}{*}{ Variable } & \multirow{2}{*}{$\begin{array}{l}\mathrm{HCV}+ \\
N=1270\end{array}$} & \multirow{2}{*}{$\begin{array}{l}\text { Control* }^{*} \\
N=5070\end{array}$} & \multirow[t]{2}{*}{$P$-value } \\
\hline & & & \\
\hline Age, median (IQR) & $47(37,53)$ & $52(47,57)$ & $<0.001$ \\
\hline Race & & & 0.99 \\
\hline White & $69.21 \%$ & $69.31 \%$ & \\
\hline Black & $20.00 \%$ & $19.90 \%$ & \\
\hline Hispanic & $3.15 \%$ & $3.14 \%$ & \\
\hline Other/not known & $7.64 \%$ & $7.65 \%$ & \\
\hline Gender (\% male) & $91.34 \%$ & $91.40 \%$ & 0.94 \\
\hline Body mass index, mean $\left(\mathrm{kg} / \mathrm{m}^{2}\right)$ & $26.94(6.73)$ & $28.15(5.98)$ & $<0.001$ \\
\hline Underweight (BMI <18.5) & $1.02 \%$ & $2.37 \%$ & 0.003 \\
\hline Normal weight (BMI 18.5-24.9) & $37.48 \%$ & $29.29 \%$ & $<0.001$ \\
\hline Overweight (BMI 25-29.9) & $39.69 \%$ & $36.21 \%$ & 0.02 \\
\hline Obese $(\mathrm{BMI}>=30)$ & $21.81 \%$ & $32.13 \%$ & $<0.001$ \\
\hline Diabetes & $4.41 \%$ & $4.73 \%$ & 0.62 \\
\hline Hypertension & $31.65 \%$ & $38.78 \%$ & $<0.001$ \\
\hline Chronic kidney disease & $13.78 \%$ & $15.50 \%$ & 0.13 \\
\hline Cardiovascular disease & $3.39 \%$ & $4.18 \%$ & 0.2 \\
\hline Alcohol abuse or dependence & $45.75 \%$ & $30.69 \%$ & $<0.001$ \\
\hline Drug abuse or dependence & $49.37 \%$ & $21.18 \%$ & $<0.001$ \\
\hline $\mathrm{ALT}$, mean (SD) & $79.31(114.08)$ & $33.28(22.48)$ & $<0.001$ \\
\hline AST, mean (SD) & $56.36(67.91)$ & $30.18(20.87)$ & $<0.001$ \\
\hline FIB-4, mean (SD) & $1.39(1.7)$ & $1.28(1.05)$ & 0.03 \\
\hline Cirrhosis by FIB-4 > 3.5 (\%) & $4.86 \%$ & $2.95 \%$ & $<0.001$ \\
\hline Total cholesterol, median (IQR) & $178.5(154.5,199.5)$ & $180(159,200)$ & 0.02 \\
\hline$>=240(\%)$ & $3.31 \%$ & $3.41 \%$ & 0.85 \\
\hline LDL, median (IQR) & 103.5(83.7,122.5) & 106(87.6,124.5) & 0.003 \\
\hline$>=190(\%)$ & $0.24 \%$ & $0.32 \%$ & 0.5 \\
\hline TG, median (IQR) & $120(84,173)$ & $110.75(77.5,159)$ & $<0.001$ \\
\hline$>=500(\%)$ & $0.31 \%$ & $0.45 \%$ & 0.5 \\
\hline $\mathrm{HDL}$, median (IQR) & $45.5(37.4,55)$ & $45.5(38,56.5)$ & 0.04 \\
\hline$<40(\%)$ & $32.20 \%$ & $30.18 \%$ & 0.16 \\
\hline HCV RNA log $10 \mathrm{IU} / \mathrm{ml}$, mean (SD) & $4.28(2.81)$ & - & - \\
\hline HCV genotype & & N/A & \\
\hline 1 & $37.40 \%$ & & \\
\hline 2 & $5.04 \%$ & & \\
\hline 3 & $6.69 \%$ & & \\
\hline 4 & $0.31 \%$ & & \\
\hline Not available & $50.55 \%$ & & \\
\hline
\end{tabular}

*Matched samples

$T C$ total cholesterol, $L D L$ low density lipoproteins, $H D L$ high density lipoprotein, $T G$ triglycerides, non- $H D L-C$ non-HDL cholesterol

categories (Fig. 3). Among $\mathrm{HCV}+$ with available genotype results, declines in lipid fractions were generally larger among genotype 3 infected persons, lowest in those with genotype 2 and intermediate in those with genotype 1 infected persons (Fig. 4). Among $\mathrm{HCV}+$ persons, after adjusting for time-updated BMI and FIB-4 score, TC cholesterol decreased by (mean [SD] mg/dL) 12.06 [36.95], LDL decreased by 9.22 [31.44], TG decreased by 13.58[87.01] and non-HDL-C decreased by 12.55 [35.14]. Among HCV-persons, TC cholesterol decreased 


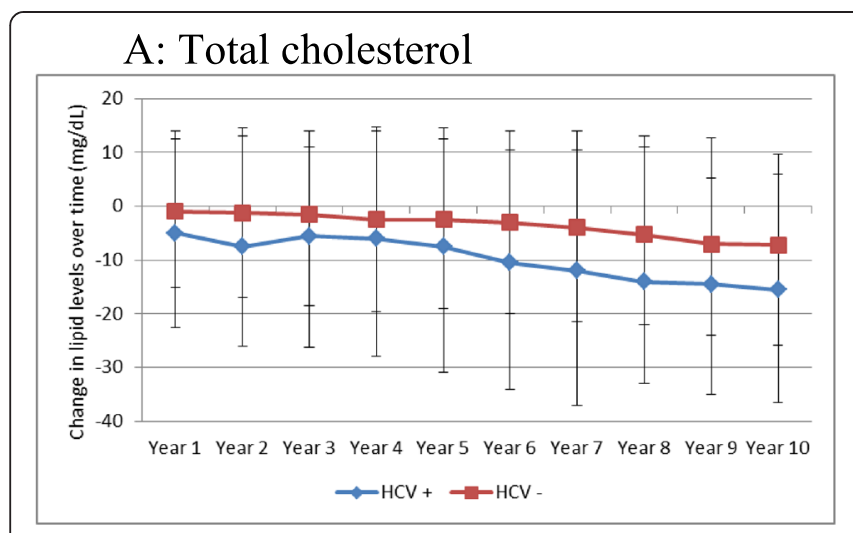

\section{C: HDL}

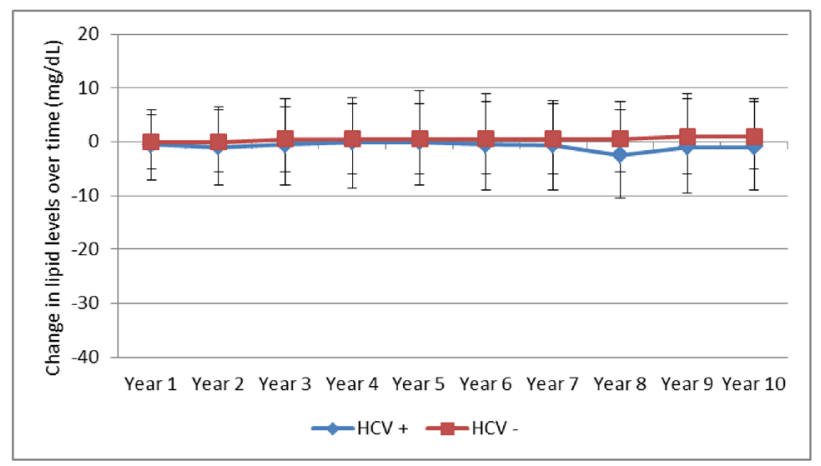

\section{E: Non-HDL-C}

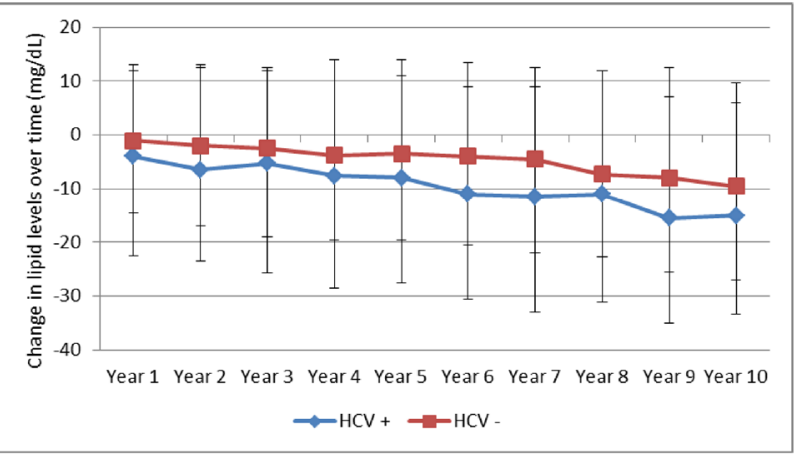

B: LDL

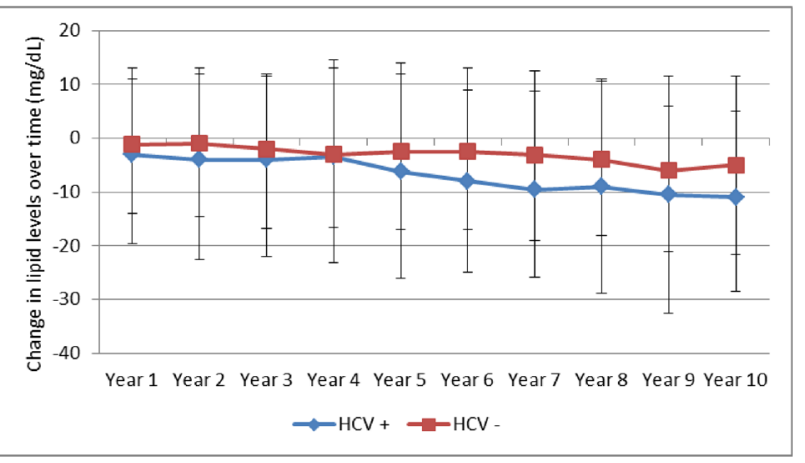

D: TG

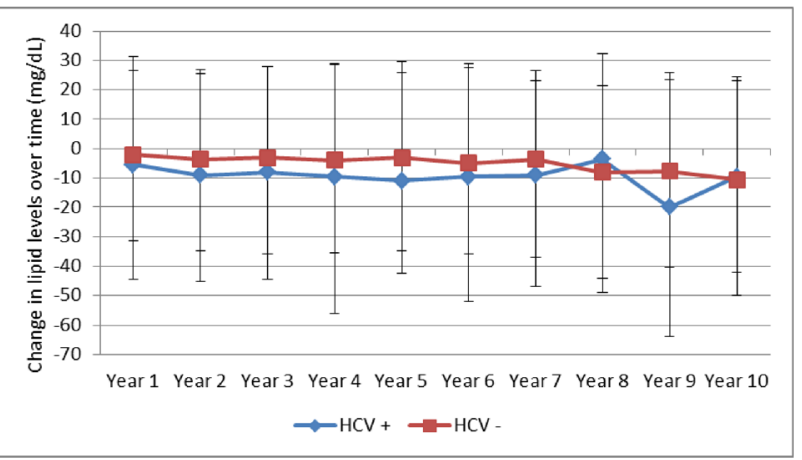

Fig. 2 Changes in lipid levels over time among HCV seroconverted and HCV uninfected persons. a Changes in total cholesterol; b Changes in LDL-cholesterol; c Changes in HDL-cholesterol; d Changes in triglycerides; e Changes in non-HDL cholesterol

by (mean [SD] mg/dL) 4.15[31.21], LDL decreased by 4.16 [26.51], TG decreased by 4.42 [82.34] and nonHDL-C decreased by 5.78 [30.17] ( $P$-value $<0.001$ for all comparisons with $\mathrm{HCV}+$ ). (Table 2) Since BMI has a significant effect on several metabolic parameters, we plotted BMI for $\mathrm{HCV}+$ and $\mathrm{HCV}$ - infected groups over time. (Additional file 1: Figure S1) The BMI in each group remained relatively stable over time and the difference between the groups that was observed at baseline appeared to remain constant. We plotted changed in lipid fractions over time in $\mathrm{HCV}+$ and $\mathrm{HCV}$ - groups adjusted for time- updated FIB-4 score, and the results were similar to the unadjusted analysis. (Additional file 2: Figure S2) We also studied the impact of HCV RNA upon lipid levels. Within the $\mathrm{HCV}+$ group, we divided subjects into tertiles based on HCV RNA levels at baseline and plotted lipid levels over time. (Additional file 3: Figure S3) No major differences were observed by HCV RNA levels.

\section{Discussion}

In this study we observed progressive decline in lipid fractions other than HDL after $\mathrm{HCV}$ seroconversion. 


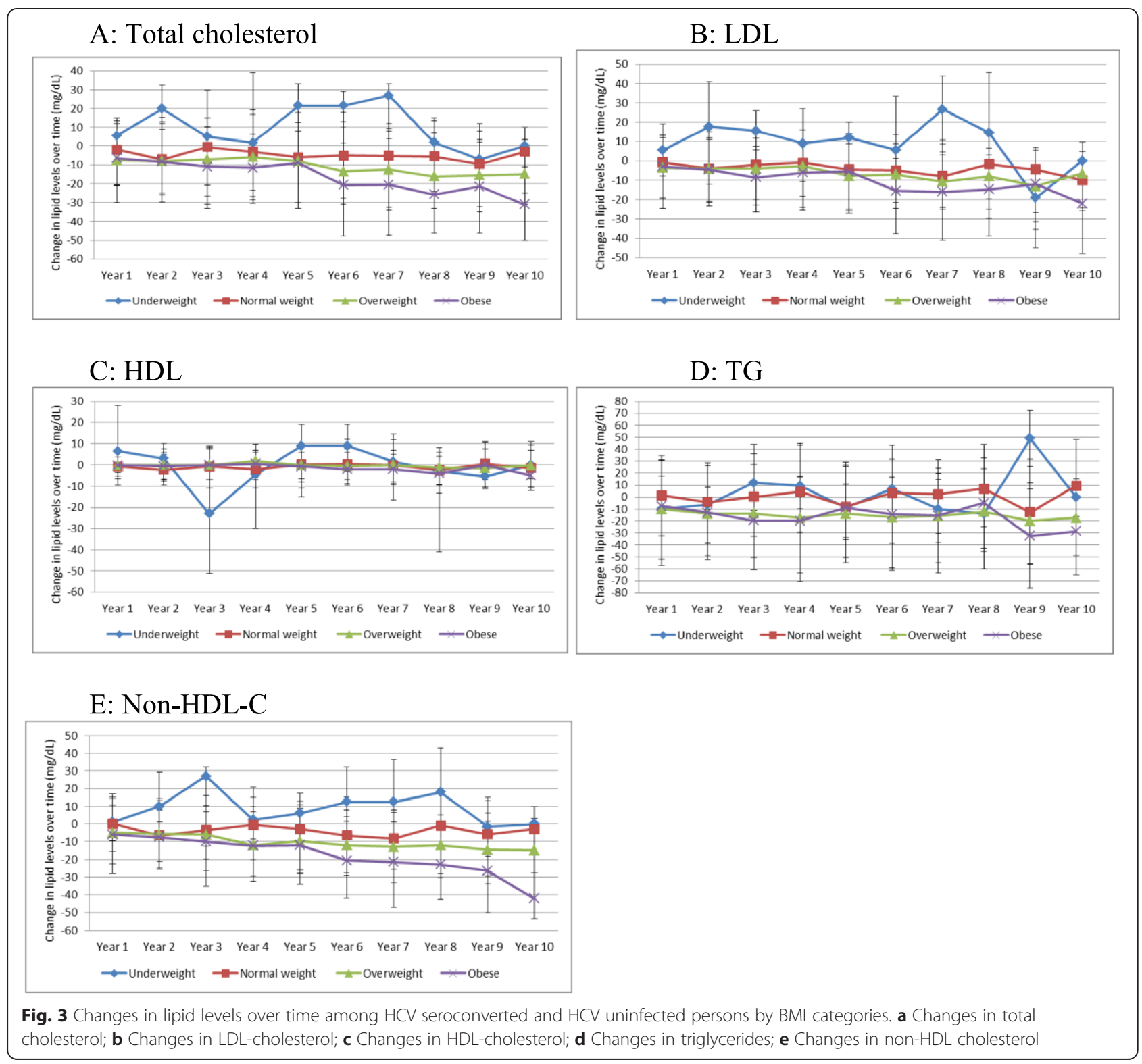

These declines were significantly more than in a demographically comparable $\mathrm{HCV}$ uninfected group, and remained significant after adjusting for BMI and degree of liver fibrosis. Within the HCV seroconverted group, the changes were generally larger in $\mathrm{HCV}$ genotype 3 infected persons, but were not related to the degree of $\mathrm{HCV}$ viremia.

Mounting evidence demonstrates a unique link between HCV and host lipid dysregulation. Patients infected with HCV have been shown to have significantly reduced levels of LDL and TC, compared to healthy matched controls and patients infected with hepatitis $\mathrm{B}$. [19-22] HCV infection has also been associated with dynamic changes in circulating lipid levels. In a recent retrospective analysis of 38 patients with acute $\mathrm{HCV}$ comparing pre- and post-infection lipid levels, those with acute $\mathrm{HCV}$ showed a significant reduction in TC and LDL levels compared to baseline. [23] In addition, the observed hypolipidemia resolved with $\mathrm{HCV}$ viral eradication; those with spontaneous or treatment-induced viral clearance had a rebound in LDL and TC to levels at or above their pre-infection baseline. [23] Such dynamic changes in lipid levels suggest a direct interaction between the virus itself and host lipid metabolism. Due to lack of knowledge of precise time or duration of infection and/or lack of an appropriate control group, previous studies do not inform us whether the changes in lipid levels are a direct consequence of $\mathrm{HCV}$ infection, or such changes are present at time of $\mathrm{HCV}$ infection or even 


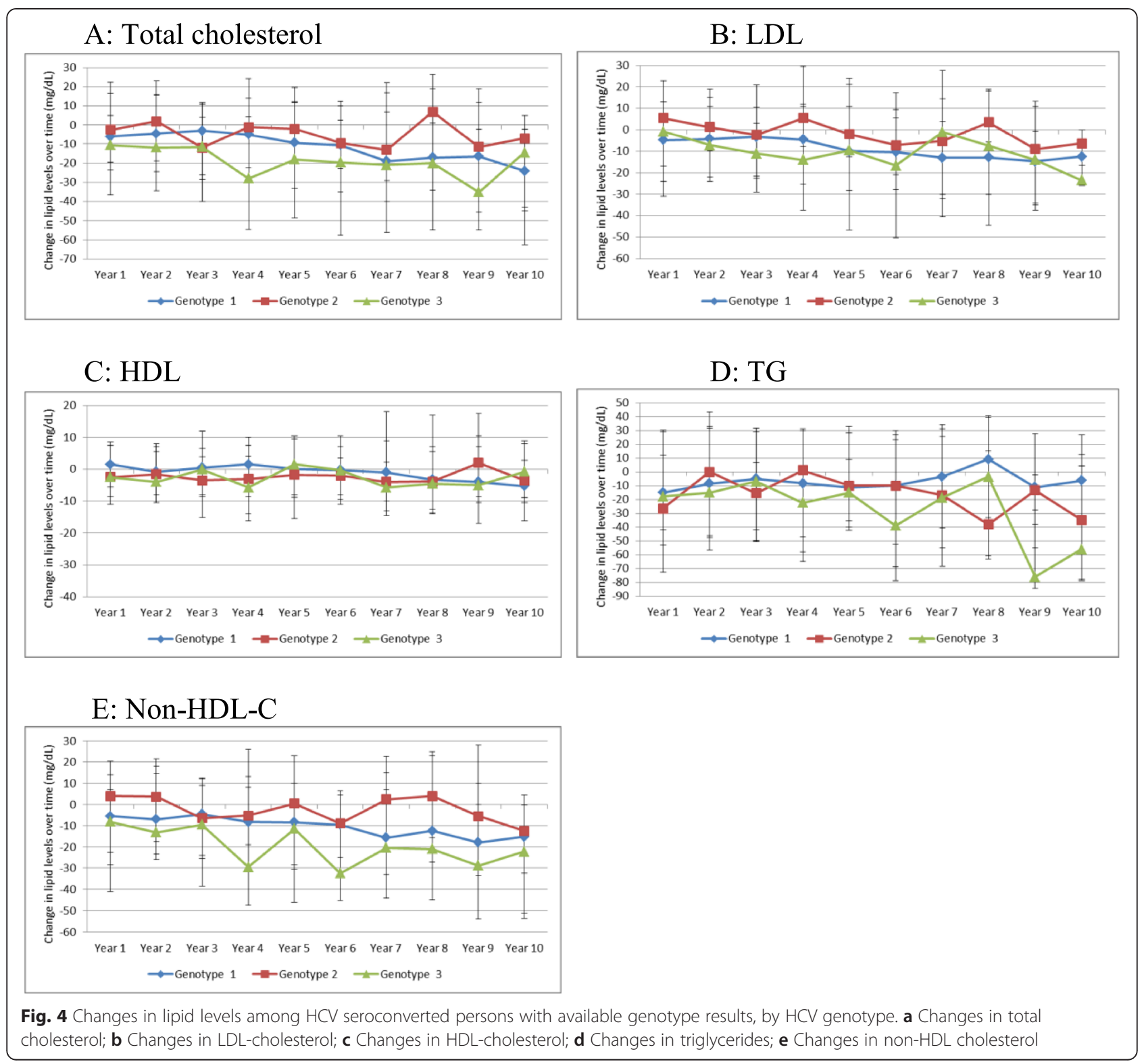

Fig. 4 Changes in lipid levels among HCV seroconverted persons with available genotype results, by HCV genotype. a Changes in tota cholesterol; b Changes in LDL-cholesterol; c Changes in HDL-cholesterol; d Changes in triglycerides; e Changes in non-HDL cholesterol

Table 2 Changes in lipid levels by HCV status over time, adjusted for time-updated body mass index, and time-updated FIB-4 score (change from baseline to last observation)

\begin{tabular}{llll}
\hline & HCV+ & HCV- & $P$-value \\
\hline TC, mean(SD), mg/dL & $-12.06(36.95)$ & $-4.15(31.21)$ & $<0.001$ \\
LDL, mean(SD), mg/dL & $-9.22(31.44)$ & $-4.16(26.51)$ & $<0.001$ \\
HDL, mean(SD), mg/dL & $0.58(17.04)$ & $1.62(15.78)$ & $<0.001$ \\
TG, mean(SD), mg/dL & $-13.58(87.01)$ & $-4.42(82.34)$ & $<0.001$ \\
Non-HDL-C, mean(SD), mg/dL & $-12.55(35.14)$ & $-5.78(30.17)$ & $<0.001$ \\
\hline
\end{tabular}

TC total cholesterol, $L D L$ low density lipoproteins, $H D L$ high density lipoprotein, TG triglycerides, non-HDL-C non-HDL cholesterol prior to that. Our study adds significantly to the current understanding by demonstrating that such changes occur predominantly after HCV seroconversion, indirect implicating a role of HCV infection in such changes. The lipid levels (TC, LDL, TG, nonHDL-C) were only marginally lower among the HCV infected group at baseline, and declined significantly more over time for HCV seroconverted persons compared with $\mathrm{HCV}$ uninfected controls. Differences in BMI alone do not fully explain this difference, since BMI remained relatively constant over time for both $\mathrm{HCV}+$ and $\mathrm{HCV}$ - groups. While the timing suggests at least a partial role of $\mathrm{HCV}$ infection in such declines, these declines do not appear related to the degree of $\mathrm{HCV}$ viremia. 
There is biological plausibility for our findings. HCV may alter cholesterol homeostasis through several mechanisms. HCV infection may produce hypolipidemia through its interference with the mevalonate pathway, resulting in decreased cholesterol synthesis. This diminished synthesis may then subsequently upregulate LDL-receptor expression, ultimately lowering LDL levels. $[19,23,24]$ Hepatitis $C$ viral proteins have been shown to directly activate the PI3-K/AKT signaling pathway, resulting in activation of the master regulator sterol response element binding protein (SREBP), which plays a critical role in activation of genes essential to fatty acid and cholesterol biosynthesis. [25-28] Additionally, infection with $\mathrm{HCV}$ is associated with reduced microsomal triglyceride transfer protein (MTTP), an enzyme critical for VLDL synthesis, and whose inhibition results in decreased circulating LDL and cholesterol levels. [29] We have previously demonstrated progressively increasing liver fibrosis among both HCV infected and uninfected Veterans, although the rate of progression and proportion of persons developing liver cirrhosis is much higher among HCV infected Veterans. [9] The aging population, particularly the Veterans in the US, have a high burden of comorbidities. High burden of comorbid illnesses, e.g. psychiatric disorders, severs CVD, cancer, etc., are associated with poor nutritional status, which in turn may lead to decreases in lipid levels.

The association of metabolic abnormalities and lipid profiles with various $\mathrm{HCV}$ genotypes is unknown. Infection with HCV genotype 3 is associated with a higher risk of hepatic steatosis, cirrhosis and hepatocellular carcinoma, but its association with insulin resistance has not been proven. [30-33] We observed a trend towards lower TC, LDL and non-HDL-C levels in HCV genotype 3 infected persons compared with $\mathrm{HCV}$ genotype 1 . The significance of this is unclear and limited by the fact that genotype results were available for less than half of $\mathrm{HCV}$ infected persons.

Certain limitations of our study need to be considered when interpreting the results. While the window of seroconversion was quite clear, the window was wide and the precise time of infection could not be determined. Lipid measurements were done as part of routine clinical care and the fasting status of subjects was not known. Some lipid fraction measurements are more affected by measurement in a non-fasting state than others. The large number of subjects and multiple measurements for each subject over time is likely to have attenuated that effect.

\section{Conclusions}

In conclusion, all lipid fractions other than HDL decline after seroconversion for HCV. Such declines are more pronounced than in comparable $\mathrm{HCV}$ uninfected persons and persist after adjusting for BMI and degree of liver fibrosis. Further studies are needed to determine if these differences in lipid levels translate into risk of cardiovascular disease and other clinical events, and to determine the need and optimal time for lipid lowering therapy in $\mathrm{HCV}$ infected persons.

\section{Additional files}

\begin{abstract}
Additional file 1: Figure S1. Changes in body mass index over time in $\mathrm{HCV}+$ and HCV-persons.(DOC $49 \mathrm{~kb}$ )

Additional file 2: Figure S2. Changes in lipid levels over time among HCV seroconverted and HCV uninfected, adjusted for time-updated FIB-4 score. (A) Changes in total cholesterol; (B) Changes in LDL-cholesterol; (C) Changes in HDL-cholesterol; (D) Changes in triglycerides; (E) Changes in non-HDL cholesterol.(DOC 109 kb)

Additional file 3: Figure S3. Changes in lipid levels among HCV seroconverted persons, by HCV RNA tertiles. (A) Changes in total cholesterol; (B) Changes in LDL-cholesterol; (C) Changes in HDL-cholesterol; (D) Changes in triglycerides; (E) Changes in non-HDL cholesterol.(DOC 126 kb)
\end{abstract}

\section{Competing interests}

AAB: grants to the institution by Gilead Sciences and AbbVie. PY, TGS, RTC and $A B A$ report no conflict of interest.

\section{Authors' contributions}

AAB: Study concept, design, data acquisition, data analysis, drafting of the manuscript, critical appraisal of the manuscript. PY: Data acquisition, data analysis, TGS: Drafting of the manuscript, critical appraisal of the manuscript. RTC, ABA: critical appraisal of the manuscript Dr. Butt had access to all data, and takes responsibility for the integrity of the work presented here. All authors have read and approve the final version of the manuscript.

\section{Acknowledgements}

This material is the result of work supported with resources and the use of facilities at the VA Pittsburgh Healthcare System and the central data repositories maintained by the VA Information Resource Center, including the National Patient Care Database, Decisions Support System Database and Pharmacy Benefits Management Database. The views expressed in this article are those of the authors and do not necessarily reflect the position or policy of the Department of Veterans Affairs.

\section{Author details}

${ }^{1}$ VA Pittsburgh Healthcare System, 3601 Fifth Avenue, Suite 3A, Pittsburgh, PA 15213, USA. 'University of Pittsburgh School of Medicine, Pittsburgh, PA, USA. ${ }^{3}$ Hamad Healthcare Quality Institute, Doha, Qatar. ${ }^{4}$ Hamad Medical Corporation, Doha, Qatar. ${ }^{5}$ Massachusetts General Hospital, Boston, MA, USA.

Received: 7 July 2015 Accepted: 5 November 2015

Published online: 11 November 2015

\section{References}

1. Butt AA, Wang X, Budoff M, Leaf DA, Kuller LH, Justice AC. Hepatitis C virus infection and the risk of coronary disease. Clin Infect Dis. 2009;49:225-32.

2. Dai CY, Yeh ML, Huang CF, Hou CH, Hsieh MY, Huang JF, et al. Chronic hepatitis $C$ infection is associated with insulin resistance and lipid profiles. J Gastroenterol Hepatol. 2013;10.

3. Siagris D, Christofidou, M, Theocharis GJ, Pagoni N, Papadimitriou C, Lekkou A, et al. Serum lipid pattern in chronic hepatitis C: histological and virological correlations. J Viral Hepat. 2006;13:56-61.

4. Forrester JE, McGovern BH, Rhee MS, Sterling RK. The individual and combined influence of HIV and hepatitis C virus on dyslipidaemia in a high-risk Hispanic population. HIV Med. 2009;10:555-63.

5. Chang ML, Tsou YK, Hu TH, Lin CH, Lin WR, Sung CM, et al. Distinct Patterns of the Lipid Alterations between Genotype 1 and 2 Chronic Hepatitis C Patients after Viral Clearance. PLoS One. 2014;9:e104783. 
6. Jung HJ, Kim YS, Kim SG, Lee YN, Jeong SW, Jang JY, et al. The impact of pegylated interferon and ribavirin combination treatment on lipid metabolism and insulin resistance in chronic hepatitis C patients. Clin Mol Hepatol. 2014;20:38-46.

7. Aizawa Y, Shimada N, Abe H, Seki N, Aida Y, Ishiguro H, et al. Serum lipoprotein profiles and response to pegylated interferon plus ribavirin combination therapy in patients with chronic HCV genotype $1 \mathrm{~b}$ infection. Hepat Mon. 2013;13:e8988.

8. Lange CM, Von WM, Bojunga J, Berg T, Farnik H, Hassler A, et al. Serum lipids in European chronic HCV genotype 1 patients during and after treatment with pegylated interferon-alpha-2a and ribavirin. Eur J Gastroenterol Hepatol. 2010;22:1303-7.

9. Butt AA, Yan P, Lo Re III V, Rimland D, Goetz MB, Leaf DA, et al. Liver fibrosis progression in hepatitis $C$ virus infection after seroconversion. JAMA Intern Med. 2015;175:178-85.

10. Butt AA, Justice AC, Skanderson M, Good CB, Kwoh CK. Rates and predictors of HCV treatment in HCV-HIV coinfected persons. Aliment Pharmacol Ther. 2006;24:585-91.

11. Butt AA, Justice AC, Skanderson M, Rigsby M, Good CB, Kwoh CK. Rate and predictors of treatment prescription for hepatitis C. Gut. 2007:56:385-9.

12. Butt AA, Khan UA, McGinnis KA, Skanderson M, Kwoh CK. Co-morbid medical and psychiatric illness and substance abuse in HCV-infected and uninfected veterans. J Viral Hepat. 2007;14:890-6.

13. Butt AA, Wang X, Moore CM. Effect of HCV and its treatment upon survival. Hepatology. 2009;50:387-92.

14. Butt AA, McGinnis KA, Skanderson M, Justice AC. Hepatitis C treatment completion rates in routine clinical care. Liver Int. 2009;30:240-50.

15. Butt AA, Wang X, Fried LF. HCV infection and the incidence of chronic kidney disease. Am J Kid Dis. 2011;57:396-402.

16. Butt AA, McGinnis KA, Skanderson M, Justice AC. A comparison of treatment eligibility for HCV in HCV monoinfected vs. HCV/HIV coinfected persons in ERCHIVES (electronically retrieved cohort of HCV infected veterans). AIDS Res Hum Retroviruses. 2011;27:973-9.

17. Erqou S, Mohanty A, McGinnis KA, Vanasse G, Freiberg MS, Sherman KE, et al. Hepatitis $C$ virus treatment and survival in patients with hepatitis $C$ and human immunodeficiency virus co-infection and baseline anaemia. J Viral Hepat. 2013;20:463-9.

18. Mohanty A, Erqou S, McGinnis KA, Vanasse G, Freiberg MS, Sherman KE, et al. Therapy for hepatitis $C$ virus infection increases survival of patients with pretreatment anemia. Clin Gastroenterol Hepatol. 2013;11:741-7.

19. Lambert JE, Bain VG, Ryan EA, Thomson AB, Clandinin MT. Elevated lipogenesis and diminished cholesterol synthesis in patients with hepatitis C viral infection compared to healthy humans. Hepatology. 2013;57:1697-704

20. Fabris C, Federico E, Soardo G, Falleti E, Pirisi M. Blood lipids of patients with chronic hepatitis: differences related to viral etiology. Clin Chim Acta. 1997;261:159-65

21. Marzouk D, Sass J, Bakr I, El HM, bdel-Hamid M, Rekacewicz C, et al. Metabolic and cardiovascular risk profiles and hepatitis $C$ virus infection in rural Egypt. Gut. 2007:56:1105-10.

22. Dai CY, Chuang WL, Ho CK, Hsieh MY, Huang JF, Lee LP, et al. Associations between hepatitis $C$ viremia and low serum triglyceride and cholesterol levels: a community-based study. J Hepatol. 2008;49:9-16.

23. Corey KE, Mendez-Navarro J, Barlow LL, Patwardhan V, Zheng H, Kim AY, et al. Acute hepatitis $C$ infection lowers serum lipid levels. J Viral Hepat. 2011;18:e366-71.

24. Corey KE, Kane E, Munroe C, Barlow LL, Zheng H, Chung RT. Hepatitis $C$ virus infection and its clearance alter circulating lipids: implications for long-term follow-up. Hepatology. 2009;50:1030-7.

25. Kim SS, Peng LF, Lin W, Choe WH, Sakamoto N, Kato N, et al. A cell-based, high-throughput screen for small molecule regulators of hepatitis $C$ virus replication. Gastroenterology. 2007;132:311-20.

26. Oem JK, Jackel-Cram C, Li YP, Zhou Y, Zhong J, Shimano H, et al. Activation of sterol regulatory element-binding protein $1 \mathrm{c}$ and fatty acid synthase transcription by hepatitis C virus non-structural protein 2 . J Gen Virol. 2008:89:1225-30.

27. Su Al, Pezacki JP, Wodicka L, Brideau AD, Supekova L, Thimme R, et al. Genomic analysis of the host response to hepatitis $C$ virus infection. Proc Natl Acad Sci U S A. 2002;99:15669-74.

28. Schaefer EA, Chung RT. HCV and host lipids: an intimate connection. Semin Liver Dis. 2013;33:358-68.
29. Mirandola S, Realdon S, lqbal J, Gerotto M, Dal PF, Bortoletto G, et al. Liver microsomal triglyceride transfer protein is involved in hepatitis $C$ liver steatosis. Gastroenterology. 2006;130:1661-9.

30. Kanwal F, Kramer JR, llyas J, Duan Z, El-Serag HB. HCV genotype 3 is associated with an increased risk of cirrhosis and hepatocellular cancer in a national sample of U.S. Veterans with HCV. Hepatology. 2014;60:98-105.

31. Tsochatzis E, Manolakopoulos S, Papatheodoridis GV, Hadziyannis E, Triantos C, Zisimopoulos K, et al. Serum HCV RNA levels and HCV genotype do not affect insulin resistance in nondiabetic patients with chronic hepatitis C: a multicentre study. Aliment Pharmacol Ther. 2009;30:947-54.

32. Milner KL, Van Der PD, Trenell M, Jenkins AB, Xu A, Smythe G, et al. Chronic hepatitis $C$ is associated with peripheral rather than hepatic insulin resistance. Gastroenterology. 2010;138:932-41.

33. Duseja A, Dhiman RK, Chawla Y, Thumburu KK, Kumar A, Das A, et al. Insulin resistance is common in patients with predominantly genotype 3 chronic hepatitis C. Dig Dis Sci. 2009;54:1778-82.

\section{Submit your next manuscript to BioMed Central and take full advantage of:}

- Convenient online submission

- Thorough peer review

- No space constraints or color figure charges

- Immediate publication on acceptance

- Inclusion in PubMed, CAS, Scopus and Google Scholar

- Research which is freely available for redistribution 